Original article

\title{
The relationship between structure and performance organizational from emergency staff viewpoints
}

\author{
Hassan Hosseinpour ${ }^{1^{*}}$, Mojtaba Tabari
}

(Receive: 20 Dec 2015; Accept: 2 Mar 2016)

\begin{abstract}
Background and Purpose: This study aimed to evaluate the relationship between organizational structure and organizational performance from the perspective of the staff of 115 emergency departments of Mazandaran province, Iran.

Materials and Methods: In this study, data were collected from the emergency personnel of different hospitals of Mazandaran province, Iran in 2014. Moreover, data on two variables of organizational performance and organizational structure were obtained using Frank's standard organizational structure questionnaire (2006). In this questionnaire, organizational structure is assessed in three dimensions of formalization, centralization, and complexity. This study was conducted on the staff of 115 emergency departments of Mazandaran province. Initially, 499 emergency personnel were selected, and sample population was determined using the Cochran's formula and random sampling. In total, 207 participants were enrolled in this study. Data analysis was performed using the Kolmogorov-Smirnov test, Spearman's correlation-coefficient, and Friedman's rank test.

Results: According to the results of Spearman's correlation-coefficient, the correlation-coefficient between organizational structure and organizational performance was 0.793 . Moreover, the correlation-coefficients of the complexity and centralization dimensions of organizational performance were 0.979 and 0.493 , respectively. Correlation-coefficient of the formalization dimension of organizational performance was obtained at 0.287 .

Conclusion: According to the results of this study, all the dimensions of organizational structure (formalization, complexity, and centralization) had significant, positive correlations with organizational performance in the viewpoint of the staff of 115 emergency departments of Mazandaran province.
\end{abstract}

Keywords: Centralization, Complexity, Emergency departments of Mazandaran province, Formalization, Organizational performance, Organizational structure

\section{Introduction}

An organization is composed of different interactive elements, education levels, and decisionmaking units. Identification and analysis of these components have been a major concern among organizational researchers (1). Setting organizational goals is essential to the structure of every institution. The structural characteristics of an organization are expressed in three dimensions of complexity, formalization, and centralization. Strengths and limitations of each of these dimensions have a significant impact on organizational structure (2).

Complexity refers to components such as the number of specialists, frequency of professional activities, and duration of vocational training courses for the staff of an organization (3). In other words, complexity focuses on the diversity of management levels in an organization. With the development of information and technology, recruitment of

\footnotetext{
1,* Corresponding author: Department of Public Administration, Master of Public Administration, Qaemshahr Branch, Islamic Azad University, Qaemshahr, Iran. Email:emshasan@yahoo.com

${ }^{2}$ Department of Management, Qaemshahr Branch, Islamic Azad University, Qaemshahr, Iran
} 
professional staff has been on the rise in different organizations, which adds to the complexity of the organizational structure (4).

Formalization refers to the rules, procedures, and written documents based on which the tasks, instructions, and commands are described for the staff of an organization. Finally, centralization concerns the low level of formal authority in individuals and organizational units. In other words, this dimension refers to the limited institutional decision-making of the employees in an organization (3).

Emergency departments are considered one of the main pillars of healthcare services. Normally, emergency departments of hospitals have excess of medical staff, which is due to the lack of attention to the structural aspect of this healthcare unit. Furthermore, medical authorities have inadequate knowledge regarding the impact of excess staff on organizational performance. This is a major obstacle against the efficiency of healthcare performance, which leads to the low quality of care services and patient dissatisfaction.

This study aimed to evaluate the relationship between organizational structure and organizational performance in 115 emergency departments of Mazandaran province by providing the necessary strategies to improve and correct the organizational structure in these units. Additionally, this could help emergency department managers to increase the efficacy of healthcare provision in this section through enhancing the organizational performance of the personnel.

Despite the advancement in information and technology, as well as the constant investigation of organizations for new methods to maximize the performance of their employees, organizational performance remains flawed in many institutions. Organizational performance largely depends on the professional efforts of the staff. In this regard, previous studies have proposed various techniques to improve the efficiency and performance of the personnel. Such examples are the behavioral promotion of employees (e.g., assignment of extra responsibilities), encouragement of personnel to adhere to rules and regulations, development and maintaining a positive attitude, and increasing the tolerance of staff against frustration and problems.

Organizational theories have confirmed that the attitude of clients in an institution increases the sense of competition among staff leading to higher organizational performance. In this regard, different theorists have used 12 key variables in order to define the structural dimensions of organizational performance. These variables include administrative components, independence, centralization, complexity, delegation, separation, formalization, professionalism, control areas, specialization, and standardization (5).

Indifferentregions ofIran, 115emergency departments are highly disciplined organizations, and the concept of organizational structure is considered a challenge in these departments. The 115 emergency departments of Mazandaran province are among the most successful healthcare organizations in our country. Since every organization, including emergency departments, seeks to optimize its function, we aimed to investigate the possible relationship between organizational structure and organizational performance from the perspective of the healthcare staff of 115 emergency departments of Mazandaran province. It is hoped that the findings of this study contribute to the enhancement of organizational performance of healthcare providers in 115 emergency departments of Mazandaran province.

The following terms need to be further elucidated:

Organizational structure: This dimension focuses on the associations between organization, authority, and communication, with the emphasis on the relationships and formal communication channels, delegation of responsibilities, and decision-making of the personnel of an organization (6).

Complexity: This dimension shows the number of management levels in an organization.

Formalization: This concept focuses on the decision-making strategies of an organization (7).

Centralization: This dimension focuses on the power distribution within an organization. In the hierarchy of authority, high-level managers have the most pivotal role in organizational decision-making.

Organizational performance: This principal concept involves the attainment of organizational and social goals and the responsibility of the authorities of an organization in this regard. 


\section{Materials and Methods}

\section{Study design and population}

Study population consisted of all the staff of 115 emergency departments of Mazandaran province in 2014. Initially, 449 healthcare workers were selected for this descriptive-correlational study (Table 1;2 ).

\section{Data collection tools}

In this study, the main data collection tool was Frank's standard organizational structure questionnaire (2006). This scale encompasses demographic characteristics (age, gender, education status, and work experience) (4 items) and different dimensions of organizational structure (complexity, formalization and concentration) (14 items). Using this questionnaire, organizational performance was evaluated based on the ranking of the performance of emergency department staff in different cities of Mazandaran province. Considering the objectives of this study, items in this questionnaire were scored based on a five-point Likert scale (Table 3 ).

\section{Reliability and validity}

Validity of a questionnaire determines whether the data collection instrument could accurately measure different characteristics of a sample population.

In this study, validity of Frank's standard organizational structure questionnaire, which is a method used to evaluate the components of a measurement tool. Content validity of a measurement tool depends on component questions. Content validity is confirmed if the questionnaire comprises of specific characteristics and skills to be measured by the researcher.

Therefore, content validity is a structural feature of measurement tools, which coincides with the development of the intertwined test within the measurement tool (8). Content validity of a test is usually assessed by experts in the predetermined subject matter. In this study, content validity of the questionnaire was confirmed by the emergency department supervisors and other management experts.

In our study, Frank's standard organizational structure questionnaire was the most important data collection tool to measure different variables, the validity of which was of paramount importance (9). Since this standardized scale has been widely used by researchers, its validity has been confirmed based on the viewpoints of the instructors of this questionnaire.

Reliability is another important technical feature of measurement tools. If a measurement tool is used several times within a short time producing similar results for a single population, the reliability of the test is confirmed. Furthermore, reliability criteria provide information regarding data collection methods, accuracy of the extracted data, and accuracy and stability of the obtained results (7).

In this study, we used the Cronbach's alpha to assess the reliability of Frank's standard organizational structure questionnaire. This method is commonly used for the calculation of the internal consistency of measurement tools to evaluate different features in a population. Cronbach's alpha coefficient is normally within the range of $0-1$, which is in fact the data correlation-coefficient at different times. In this range, one is considered the maximum correlation value, while zero shows lack of correlation. In a measurement tool, answers to each question could adopt different values of Cronbach's alpha coefficient.

To determine the Cronbach's alpha coefficient in this study, we initially calculated the variance of each score achieved in the sub-tests of the questionnaire and total variance. Afterwards, the alpha coefficient was calculated using the following formula:

$r_{a}=\frac{j}{j-1}\left(1-\frac{\sum S_{j}^{2}}{S^{2}}\right)$

In this formula, $J$ represents the number of subtests in the questionnaire, is the sub-test of the $J$ variance, and $\mathrm{S}^{2}$ represents the total variance of the test.

Cronbach's alpha coefficient is the most common technique to determine test reliability, which was used in our study. In total, 30 questionnaires were distributed among the participants of this study between data collection and calculation of Cronbach's alpha coefficient. Cronbach's alpha reliability coefficient is within the range of $0-1$, in 
which zero indicates lack of reliability, and one is interpreted as total reliability.

In this study, data analysis via SPSS was indicative of the high reliability of Frank's standard organizational structure questionnaire, and the Cronbach's alpha coefficient was calculated to be 0.81 for this questionnaire (Table 4).

In this study, required data were collected using the standard organizational structure questionnaire, which was developed by Frank in 2006. This questionnaire consists of 14 items that are scored based on a five-point Likert scale (Strongly Disagree, Disagree, Do Not Know, Agree, and Strongly Agree) within a score range of 1-5 (Table 5).

\section{Data analysis}

In this study, data analysis was performed in SPSS V.16 using descriptive and inferential statistics. Moreover, the Kolmogorov-Smirnov test was used to assess the distribution frequency of the collected data, and Pearson's correlation-coefficient was applied to evaluate test case factors.

\section{Results}

\section{Statistical descriptions of study population}

Among 207 respondents in this study, 28 subjects were female, and 179 were male. In terms of education status, 81 participants had high school diploma or an associate degree, 112 subjects had bachelor's degree, and 14 participants were graduates or had higher education. Moreover,
54 participants were aged less than 30 years, 117 subjects were within the age range of 30-45 years, and 36 participants were aged above 45 years.

In this study, 41 participants had work experience of less than 5 years, 64 subjects had work experience of 5-10 years, 74 subjects had work experience of 10-15 years, 20 participants had work experience of 15-20 years, and 8 subjects had more than 20 years of work experience.

\section{Normality test of components}

Results of the Kolmogorov-Smirnov test are presented in Table 6. According to the information in this table, level of significance for all the studied variables was more than 0.05 . Therefore, it is confirmed that the studied variables were normal in the Kolmogorov-Smirnov test (Table 6).

According to the results of this study, mean scores of organizational structure, complexity, centralization, formalization and organizational performance were $3.905,3.539,4.157,3.966$, and 3.603 , respectively.

There was a significant association between organizational structure and organizational performance in the viewpoint of the staff of 115 emergency departments of Mazandaran province.

There was a significant correlation between the complexity dimension and organizational performance in the viewpoint of the staff of 115 emergency departments of Mazandaran province.

There was a significant association between the centralization dimension and organizational

Table 1. Frequency of study population based on different cities of Mazandaran province

\begin{tabular}{|c|c|c|c|c|c|c|c|c|c|c|c|c|c|c|c|c|}
\hline 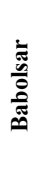 & 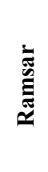 & 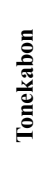 & $\overline{\tilde{E}}$ & 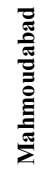 & 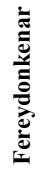 & 高 & 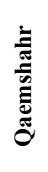 & $\frac{\frac{\pi}{4}}{\mathrm{z}}$ & 离 & 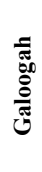 & $\begin{array}{l}\frac{\vdots}{\bar{J}} \\
\frac{\vec{\pi}}{\bar{b}} \\
z\end{array}$ & 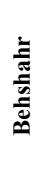 & $\overline{\mathrm{O}}$ & $\frac{\tilde{E}}{\frac{\tilde{E}}{\tilde{J}}}$ & $\begin{array}{l}\bar{\Xi} \\
\bar{z} \\
\bar{z} \\
\tilde{E} \\
\tilde{E}\end{array}$ & స్ \\
\hline 18 & 14 & 17 & 112 & 16 & 8 & 28 & 22 & 16 & 7 & 10 & 13 & 28 & 55 & 52 & 33 & 449 \\
\hline
\end{tabular}

Table 2. Statistical distribution of study samples based different cities of Mazandaran province

\begin{tabular}{|c|c|c|c|c|c|c|c|c|c|c|c|c|c|c|c|c|}
\hline 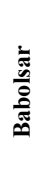 & 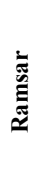 & 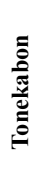 & $\begin{array}{l}\bar{\Xi} \\
\tilde{n}\end{array}$ & 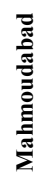 & 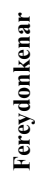 & $\dot{\grave{a}}$ & 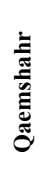 & $\frac{\pi}{z}$ & 㷰 & 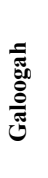 & 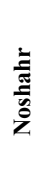 & 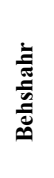 & $\overline{\stackrel{\theta}{g}}$ & 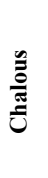 & 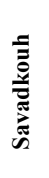 & हुँ \\
\hline 8 & 6 & 8 & 53 & 7 & 4 & 13 & 10 & 7 & 3 & 5 & 6 & 13 & 25 & 24 & 15 & 207 \\
\hline
\end{tabular}


Table 3. Organizational performance scores of emergency department staff in different cities of Mazandaran province during 2010-2014

\begin{tabular}{lc}
\hline City & Score \\
\hline Babolsar & 16 \\
\hline Ramsar & 17 \\
\hline Tonekabon & 14 \\
\hline Sari & 15 \\
\hline Mahmoudabad & 16 \\
\hline Fereydonkenar & 12 \\
\hline Noor & 7 \\
\hline Qaemshahr & 10 \\
\hline Neka & 5 \\
\hline Jouybar & 6 \\
\hline Galoogah & 7 \\
\hline Noshahr & 5 \\
\hline Behshahr & 5 \\
\hline Amol & 5 \\
\hline Chalous & 5 \\
\hline Savadkouh & 5 \\
\hline
\end{tabular}

performance in the viewpoint of the staff of 115 emergency departments of Mazandaran province.

There was a significant correlation between the formalization dimension and organizational performance in the viewpoint of the staff of 115 emergency departments of Mazandaran province.

According to the information in Table 7, the correlation-coefficient of organizational structure and organizational performance was 0.793 . Considering the significance level of $<0.05$, a statistically significant correlation was observed between organizational structure and organizational performance. In this regard, the positive correlationcoefficient was indicative of the direct correlation of these two components. Since this value was more than 0.7 , this correlation was considered powerful.

On the other hand, the correlation-coefficient of the complexity dimension and organizational performance was estimated at 0.979 . Considering the significant level $(0.000)$ of $<0.05$, a statistically

Table 4. Cronbach's alpha coefficient

\begin{tabular}{lcc}
\hline Questionnaire & Number of samples & Cronbach's alpha \\
\hline Organizational structure & 30 & 0.81 \\
\hline Formalization dimension & 30 & 0.74 \\
\hline Centralization dimension & 30 & 0.90 \\
\hline Complexity dimension & 30 & 0.79 \\
\hline
\end{tabular}

significant correlation was observed between the complexity dimension in organization and organizational performance. In this regard, the positive correlation-coefficient was indicative of a direct correlation between these two components. Since this value was close to one, this correlation was considered to be powerful.

In this study, the correlation-coefficient of the dimension of centralization in organization and organizational performance was determined at 0.493. Considering the significance level $(0.000)$ of $<0.05$, a statistically significant correlation was observed between the centralization dimension and organizational performance. In this regard, the positive correlation-coefficient was indicative of a direct correlation between these two components. Since this value was close to the constant value of 0.5 , this correlation was considered to be powerful.

Finally, the correlation-coefficient of the formalization dimension in the organization and organizational performance was calculated to be 0.287 . Considering the significance level $(0.000)$ of $<0.05$, a statistically significant correlation was observed between formalization and organizational performance. In this regard, the positive correlationcoefficient was indicative of a direct correlation between these two components. Since this value was less than 0.3 , this correlation was considered to be weak (Table 7).

\section{Discussion}

Considering the hypotheses obtained in the present study, organizational structure in the dimensions of complexity, formalization and centralization had an association with the organizational performance of healthcare staff of 115 emergency departments of Mazandaran province. In this regard, the findings of Nayebzadeh and Salari Abargouei (2014), Majidi

Table 5. Corresponding questionnaires

\begin{tabular}{lccc}
\hline Scale & Subscale & Scale measure & Questionnaire \\
\hline \multirow{2}{*}{$\begin{array}{l}\text { Organizational } \\
\text { structure }\end{array}$} & Complexity & Five-point Likert scale & $10-14$ \\
\cline { 2 - 4 } & Formalization & Five-point Likert scale & $1-5$ \\
\cline { 2 - 4 } & Centralization & Five-point Likert scale & $6-9$ \\
\hline $\begin{array}{l}\text { Organizational } \\
\text { performance }\end{array}$ & $\begin{array}{l}\text { Evaluation of organizational performance based on ranking } \\
\text { of emergency departments in cities of Mazandaran province }\end{array}$ \\
\hline
\end{tabular}


Table 6. Results of Kolmogorov-Smirnov test

\begin{tabular}{lccccc}
\hline Organizational structure & Complexity & Centralization & Formalization & Organizational performance & Number \\
\hline 207 & 207 & 207 & 207 & 3.603 & Mean \\
\hline 3.905 & 3.539 & 4.157 & 3.966 & 0.703 & Normal parameter \\
\hline 0.468 & 0.715 & 0.484 & 0.612 & 1.054 & Standard deviation \\
\hline 1.076 & 0.863 & 1.031 & 1.007 & 0.216 & Kolmogorov-Smirnov test results \\
\hline 0.198 & 0.445 & 0.218 & 0.221 & Significance level \\
\hline
\end{tabular}

Table 7. Correlations between organizational structure and organizational performance

\begin{tabular}{|c|c|c|c|}
\hline & & $\begin{array}{c}\text { Organizational } \\
\text { performance }\end{array}$ & $\begin{array}{l}\text { Organizational } \\
\text { structure }\end{array}$ \\
\hline \multirow{2}{*}{$\begin{array}{l}\text { Organizational } \\
\text { performance }\end{array}$} & $\begin{array}{l}\text { Pearson's } \\
\text { significant }\end{array}$ & 1 & $\begin{array}{l}0.793 \\
0.000\end{array}$ \\
\hline & sample size & 207 & 207 \\
\hline \multirow{2}{*}{$\begin{array}{l}\text { Organizational } \\
\text { structure }\end{array}$} & Pearson's & 0.793 & 1 \\
\hline & $\begin{array}{l}\text { significant } \\
\text { sample size }\end{array}$ & $\begin{array}{c}0.000 \\
207\end{array}$ & 207 \\
\hline \multirow{2}{*}{$\begin{array}{l}\text { Organizational } \\
\text { performance }\end{array}$} & Pearson's & 1 & 0.979 \\
\hline & $\begin{array}{l}\text { S1gnificant } \\
\text { sample size }\end{array}$ & 207 & $\begin{array}{c}0.000 \\
207\end{array}$ \\
\hline \multirow{3}{*}{ Complexity } & Pearson's & 0.979 & 1 \\
\hline & significant & 0.000 & \\
\hline & sample size & 207 & 207 \\
\hline \multirow{3}{*}{ Performance } & Pearson's & 1 & 0.493 \\
\hline & significant & & 0.000 \\
\hline & sample size & 207 & 207 \\
\hline \multirow{3}{*}{ Centralization } & Pearson's & 0.493 & 1 \\
\hline & significant & 0.000 & \\
\hline & sample size & 207 & 207 \\
\hline \multirow{2}{*}{$\begin{array}{l}\text { Organizational } \\
\text { performance }\end{array}$} & Pearson's & 1 & 0.287 \\
\hline & $\begin{array}{l}\text { Significant } \\
\text { sample size }\end{array}$ & 207 & $\begin{array}{c}0.000 \\
207\end{array}$ \\
\hline \multirow{3}{*}{ Formalization } & Pearson's & 0.287 & 1 \\
\hline & significant & 0.000 & \\
\hline & sample size & 207 & 207 \\
\hline
\end{tabular}

et al. (2011), and Khalili Iraqi et al. (2009) are in congruence with the results of the current study $(6,10,11)$.

In general, all public and private healthcare institutions and organizations, especially 115 emergency departments of Mazandaran province, are the beneficiaries of the obtained results of the present study. Therefore, it is recommended that new organizational structures be implemented in 115 emergency departments of Mazandaran province in order to improve the performance of this medical unit. This could result in high-quality care services and reduced complexity of the organization. Furthermore, direct involvement of the emergency staff in decision-making could improve access to emergency services and organizational performance, while reducing complexity or organizational recognition could increase the performance. It is hoped that the findings of the current study lay the ground for the promotion of organizational performance in 115 emergency departments of Mazandaran province and provision of immediate high-quality services in these healthcare units.

\section{Study limitations}

Limitation in the sample population due to the selection of the participants from the personnel of 115 emergency departments of Mazandaran province only.

Inherent limitations of the questionnaire as the main measurement tool, which did not allow the quantification of some qualitative issues related to the research subject.

Effects of the level of intelligence, interest, and scientific and technical abilities of participants on their responds to questionnaire items.

Time-consuming distribution of the questionnaires and data collection.

Conscious or unconscious conservativeness of some of the emergency staff in completing the questionnaires due to concerns regarding the disclosure of study results.

Effects of factors related to the socioeconomic and cultural characteristics of the participants on the final results of the study.

\section{Conclusion}

Conducting a purely scientific study in the field of management and behavioral sciences is not possible. This could be due to the problems associated with the measurement and collection of data on subjective grounds, as well as the effect of the emotions, attitudes and perceptions of individuals on the final results. In case of these 
problems, researchers should attempt to quantify actual human behaviors. In this regard, since identification of a proper sample population might be difficult, generalization of the obtained data might not be possible. This is due to the fact that all the required scientific features could not be found in all sample populations. In the field of research, comparability, reliability, and generalization of findings are complicated concepts and processes. Moreover, in scientific research, implementation of factors such as study design, degree of focus, strength and maximum testability, repeatability, data generalization, objectivity, efficiency, accuracy and reliability requires utmost attention and meticulous observation (12).

\section{Conflicts of interest}

None declared.

\section{Author's contributions}

$\mathrm{H}$ Hoseinpour contributed to study conception and design, data collection and analysis, and writing the manuscript. M Tabari supervised and edited the manuscript.

\section{Acknowledgements}

We would like to thank 115 Emergency Department of Mazandaran province, Iran, for their cooperation.

\section{References}

1. Daft RL, Marcic D. Understanding management. India:
Cengage Learning; 2006.

2. Erfannia M. The impact of structural factors on labor productivity. Tadbir J 2004; 15(146):88 (Persian).

3. Rezaeian A. The age of human and social capital. Tehran: Management Message; 2004. P. 5-22.

4. Jadidi R, Memari F, Anbari Z. The relationship between organizational structure and organizational intelligence in teaching hospitals of Arak Medical Sciences. Arak Med Univ J 2013; 16(8):21-31 (Persain).

5. Mihm J, Loch $\mathrm{CH}$, Wilkinson $\mathrm{D}$, Huberman BA. Hierarchical structure and search in complex organizations. Manag Sci 2010; 56(5):831-48.

6. Nayebzadeh S, Salari Abargouei M. The relationship between strategy-structure fit and performance in family firms (case study: family firms based in the industrial town of Yazd province). J Manag Sys 2014; 1(3):1-12 (Persian).

7. Mirabi VR, Jamshidi M, Godarzi P, Yosefi S. The organizational citizenship behavior of the faculty members. J Busin Manag 2010; 2(7):149-81 (Persian).

8. Khaki GR. Methodology with an approach on writing a thesis. 2nd ed. Tehran: Domestic Scientific Research Center; 2010.

9. Hafeznia MR. An introduction to research methods in the humanities. 10th ed. Tehran: Samt; 2004 (Persian).

10. Majidi A. The effect of organizational structure on performance of the Police training, department. J Manag Train 2011; 7(12):78-85 (Persian).

11. Khalili AM, Akbari MB, Ataollahi M. The effect of environmental risks, corporate strategy andcapital structure on firm performance in petro chemistry industry. J Dev Evalut Manag 2009; 1(1):41-7 (Persian).

12. Sakaran U, Sabian M, Shirazi M. Higher institute of management and planning education and research. Tehran: Management Research Institute; 2009. 